\title{
An Analysis of the Factors Affecting the Adoption of Accounting Legislation by Small and Medium-Sized Enterprises (SMES) in Vietnam
}

\author{
Tran Thi Thanh Hai ${ }^{1}$ \\ ${ }^{1}$ University of Economics Hochiminh City, Vietnam \\ Correspondence: Tran Thi Thanh Hai, University of Economics Hochiminh City, Vietnam. E-mail: \\ luulihaithanh@yahoo.com or thanhhai@ueh.edu.vn
}

Received: December 3, 2014

Accepted: December 16, 2014

Online Published: January 20, 2015

doi:10.5539/ijbm.v10n2p176

URL: http://dx.doi.org/10.5539/ijbm.v10n2p176

\begin{abstract}
The purpose of this paper is to identify the factors affecting the adoption of accounting legislation by Vietnamese SMEs. The process of qualitative and quantitative research with Exploratory Factor Analysis (EFA) procedures, reliability test of the rating scale with Cronbach's Alpha coefficients and regression analysis showed that: the main factors affecting the application of accounting legal framework to Vietnamese SMEs are indicated as follows: accounting infrastructure, mandatory compliance of these regulations, accountants, cost-benefit relationship and the accounting legislation itself.
\end{abstract}

Keywords: SMEs, Vietnam, accounting legislation

\section{Introduction}

With a view to facilitate accounting tasks as well as ensure truthful and rational economic information, it is of the essence to study and promulgate complete a legal documents system guiding the implementation of accounting tasks in the enterprises, especially in SMEs. However, due to such barriers as economic characteristics, the legal system as well as the accountants' capacity and habits, it is still a challenging process from the phase of promulgation of these regulations to that of their application in practice (Choi et al., 2011; according to Tran D. K. Nguyen, 2013). Hence, it is equally important to study the factors affecting this implementation, based on which a number of viable solutions can be considered to enhance the efficiency of accounting legislation in SMEs.

\section{Literature Review}

\subsection{Small and Medium Enterprises}

In Vietnam, according to the Decree No. 56/2009/ND-CP, SMEs are generally defined as a registered business establishment prescribed by law and are divided into 03 scales namely: micro, small and medium according to the total capital (the total capital is equal to the total assets specified in the balance sheet) or the average number of labourers per year. Details are as follows.

Table 1. Definition of SMEs in Vietnam

\begin{tabular}{|c|c|c|c|c|c|}
\hline \multirow{2}{*}{$\begin{array}{l}\text { Type of } \\
\text { SMEs } \\
\text { Sector }\end{array}$} & \multirow{2}{*}{$\begin{array}{l}\text { Micro } \\
\text { Number of } \\
\text { labourers }\end{array}$} & \multicolumn{2}{|l|}{ Small } & \multicolumn{2}{|l|}{ Medium } \\
\hline & & Total capital & $\begin{array}{l}\text { Number of } \\
\text { labourers }\end{array}$ & Total capital & $\begin{array}{l}\text { Number of } \\
\text { labourers }\end{array}$ \\
\hline $\begin{array}{l}\text { I. Agriculture, Forestry } \\
\text { and Fishery }\end{array}$ & $\leq 10$ & $\leq 20$ billion VND & 10 to 200 & $\begin{array}{l}20 \text { to } 100 \text { billion } \\
\text { VND }\end{array}$ & 200 to 300 \\
\hline $\begin{array}{l}\text { II. Industry and } \\
\text { Construction }\end{array}$ & $\leq 10$ & $\leq 20$ billion VND & 10 to 200 & $\begin{array}{l}20 \text { to } 100 \text { billion } \\
\text { VND }\end{array}$ & 200 to 300 \\
\hline III. Trade and Service & $\leq 10$ & $\leq 20$ billion VND & 10 to 50 & $\begin{array}{l}20 \text { to } 50 \text { billion } \\
\text { VND }\end{array}$ & 50 to 100 \\
\hline
\end{tabular}

Source: Decree No. 56/2009/ND-CP dated June $30^{\text {th }} 2009$ of the Government. 


\subsection{The Accounting Legal Framework for Vietnamese SMEs}

Vietnamese accounting system is influenced by continental European system in general and French accounting in particular. In Vietnam, the Ministry of Finance (a state agency) is an organization responsible for issuing legal documents in accounting. The legal framework regulating the accounting practices of SMEs include: Accounting Law and guiding the implementation of Decree Law; The system of accounting standards and the standards guidelines; and accounting regime. Vietnamese SMEs are required to comply with these domestic GAAP developed by the national regulator. However, the proportion of businesses fully complied in practice is rather low. The Vietnamese GAAP are based on historical cost criterion and fair value is only used in a few cases.

\subsection{Factors Influencing the Application of Accounting Legislation}

Several previous studies have spent great effort to investigate the factors affecting the application of accounting legislation into the reality. Internationally speaking, numerous studies were conducted to investigate this issue, mainly concentrating on the application of accounting standards. Most of these factors relates to corporate characteristics such as: scale (Chow \& Wong-Boren, 1987; Cooke, 1991); profitability (Belkaoui \& Kahl, 1978; Singhvi \& Densai, 1971; Wallace \& Naser, 1995); the awareness of corporate's owner (Page, 1984; Collis \& Jarvis, 2000); educational competency (Doupnik \& Salter, 1995); debt structure (Sekely \& Collins, 1998). These researches were, however, conducted in the countries that belong to an Anglo-American culture, or in the developed countries (Tran D. K. Nguyen, 2011).

There are a limited number of experimental studies on the factors having effect on the application of accounting legal framework in SMEs at a certain country. Published studies primarily focus on the analysis of macroeconomic factors, national specificities as well as the factors affecting the implementation of international accounting standards. As a result of our synthesis from the published scientific papers and research works, we can possibly identify a number of factors influencing the application of accounting legislation in SMEs, to be more specific:

Initially, accountants themselves have a significant impact on the utilization of accounting legal documents. According to numerous researches, accountants and their professional capacity play a crucial role, in which their assessment and professional judgment are the key factors (Bunea, 2006; according to Cătălin Nicolae Albu, 2010). As the direct "producers" of information, the professional competence and responsibility of the accounting department is positively correlated with the quality of information they provide. In the advent of inadequate professional capability, the deficient cognition of accountants can result in misinterpretation and incomplete utilization of the legal regulations; as a consequence, the implementation of these legal documents is inefficient. Considering such important role, accountants' skills in most enterprises are yet limited (Joshi \& Ramadhan, 2002; Martin, 2005; according to Dang Duc Son, 2011). Also in agreement with this viewpoint, the research result of Albu et al. (2010) in Romania (a country whose economic development and accounting system are similar with those of Vietnam) specified that accountants' capacity has a critical influence on the application of accounting standards into practice.

Next, corporate scale is also a factor that has a profound impact on the deployment of accounting legislation. Albu et al. (2010) quoted from the study of Haller and Eirle (2008) stated that: the bigger the corporate scale is, the higher the information transparency, the accountability, the compliance with accounting and auditing regulations as well as the disclosure of information become. Sian and Roberts (2009) indicated that there exists a correlation between the corporate scale and the complexity of accounting tasks. It can be easily noted that large enterprises are generally bound by numerous accounting rules, regulations and requirements that serve to ensure the reliability of financial information. Meanwhile, SMEs are treated dissimilarly due to their simplicity in operation and low risk from internal and external sources. This difference leads to asymmetric information between corporate owner-managers and stakeholders who primarily are creditors and the government; accordingly, minor concern is spent on the information quality in financial report. In addition, as stated in a number of researches (Chow \& Wong-Boren; 1987, Cooke, 1989, 1991; Meek \& Gray, 1995), there is a consensus that corporate scale is considered as a compelling source of impact on the implementation of accounting standards (Tran D. K. Nguyen, 2010). Thus, we indicate corporate scale as a factor in our model to investigate the factors affecting the application of accounting legislation in SMEs in Vietnam.

Besides, the users and their needs of accounting information also influence the quality of accounting information. This factor has an indirect effect on the utilization of accounting legislation in order to generate transparent and user-friendly accounting information. It is vital to assure the quality of financial report as a financial report will become worthless if its users deems it as worthless (Ha van Wyk, 2009). Zeghal and Mhedhbi (2006) conducted their research with a sample comprising 64 developing countries. Their result revealed a number of determining 
factors that have considerable effect on applying international standards, such as: educational level, the existence of capital market and cultural membership in a group of countries. This study further indicated that in their effort to provide the investors with qualified accounting information, developing countries along with their capital market meet less difficulty in the implementation of international accounting standards. This statement proves that user's need of information does have a positive influence on the deployment of accounting legal framework in enterprises, especially in SMEs.

In addition, another factor called educational level also affects the utilization of accounting standards in developing countries as this factor exerts a direct influence on managers' cognition, accountants' skills as well as the awareness of information users. The study of Jiri Strouhal (2012) in Czech Republic proved that the application of accounting standards is partially influenced by users' pressure on accounting information as well as the relationship between paid expense and received benefits. Dang Duc Son (2011) also carried out a research to investigate the application of accounting standards in SMEs in Vietnam. The research findings revealed 05 major factors affecting this application, among which the mandatory compliance and external pressure on improved information are 02 key factors. Additionally, the deficiency in managing and accounting skills, lack of infrastructure, cost and benefit relationship and pressure on information are other factors that count. Nonetheless, the biggest drawback of this research is its narrow sample and its primary concentration on accountants which are responsible for the limited generalization of this research.

Furthermore, accounting infrastructure is the fundamental systems and services needed for proper and successful accounting practices including professional organization, accounting training system, etc. A developed accounting infrastructure can best facilitate these accounting practices and enhance the effective application of documents into the reality.

In summary, each author has his own assumption of the determining factors in the process of applying accounting legislation in SMEs, factors varies depending on each country, each investigated object or each environment where the research is conducted. However, by common concurrence, there are a number of major factors as follows: The degree of economic and educational development; how open the economy is; accountant's knowledge, skills and experience; corporate scale; manager's perspective and need of information; mandatory compliance; accounting infrastructure; cots and benefit relationship; user's pressure on information supply and finally, the content of legal documents themselves.

In Vietnam, when it comes to the application of legal documents to SMEs, the investigation starts from the methodology used by these enterprises, how they manipulate that process and its efficiency regarding the implementation of accounting legislation, accounting standards, accounting regime and the related legal documents. Within the scope of this article, the authors place focus on the investigation of the aforementioned factors and their impacts on the deployment of accounting legislation in SMEs. Based on the survey of expert opinions, some factors with macro nature are deemed to have no direct impact and therefore are excluded; factors that are similar to some extent are categorized into groups; ultimately the authors conclude 8 major factors namely: the legal framework itself, mandatory compliance, corporate scale, business owner - manager, accountants, user's pressure on information supply, cost and benefit relationship, factors relating to accounting infrastructure. These factors are proposed based on the findings of the previously published studies with appropriate adjustment considering the actual accounting practices in SMEs and the eco-political characteristics of Vietnam, as well as based on the results of qualitative studies through expert opinions. On this basis, we proposed the following model under examination: 


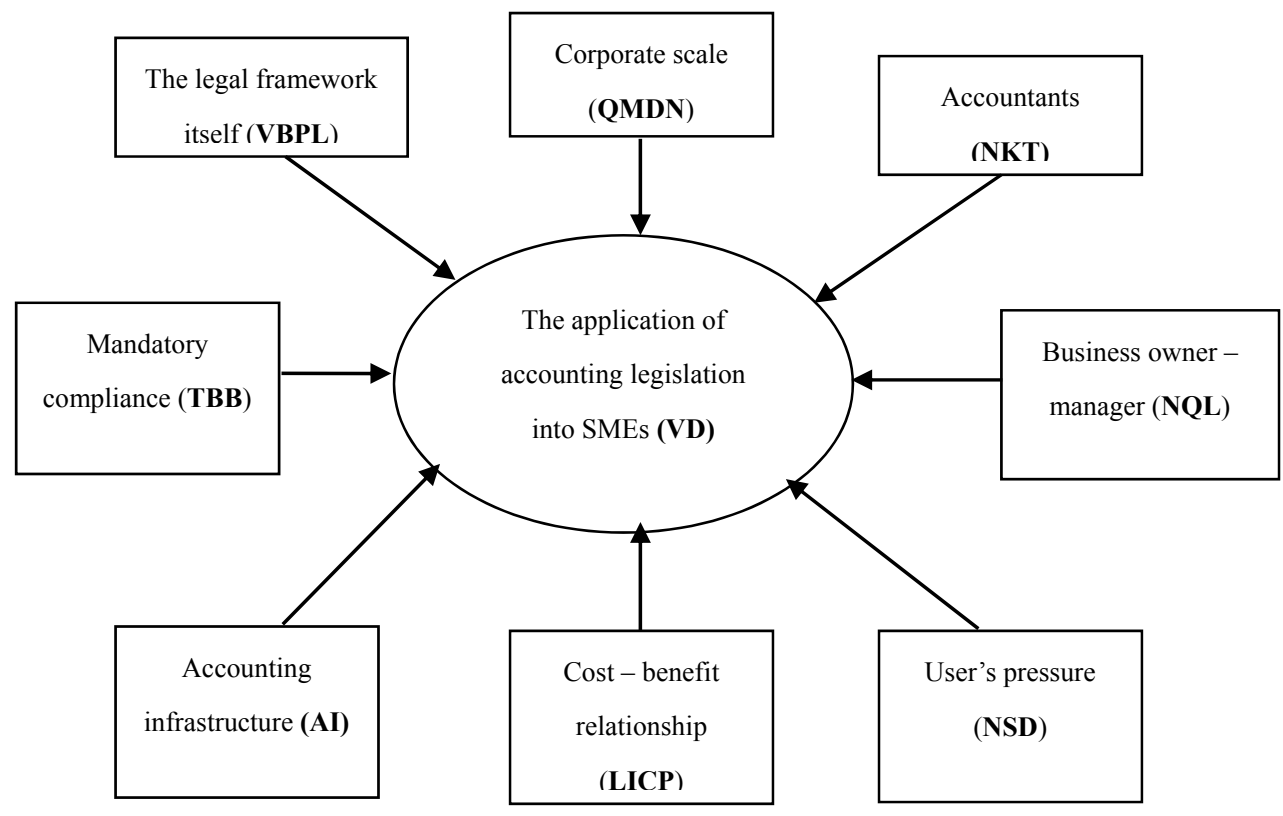

Figure 1. Proposed model of factors affecting the application of accounting legal legislation to the actual accounting practices in SMEs

\section{Data and Research Methodology}

Data was collected from the survey conducted in the $3^{\text {rd }}$ quarter of 2013 in Ho Chi Minh City, the largest national economic centre of Vietnam and also the home to a huge number of SMEs. SMEs involved were a convenience sample in accordance with criteria stated in the Decree No. 56/2009/ND-CP dated June 30th 2009 by the Government. After the exclusion of invalid survey panels, the total quantity of qualified panels is 548 panels which are sufficient to assure the credibility of data analysis.

So as to achieve the initial objectives of this article, in this study we chiefly use quantitative methodology, in addition to this, qualitative methodology is used as a supplement.

The qualitative research method was adopted with expert interview technique. In order to generalize various factors from different categories, we collected opinions from diversifying subject groups, namely: accountants directly engaged with accounting practices at SMEs, managers of SMEs, researchers and lecturers on accounting, officers in charge of enterprise management department in taxation offices. On the basis of this step, we developed the draft of our survey panel. From this stage onwards, we carried out various trials to deliver a complete questionnaire, these additional steps include: trial surveys based on the devised questionnaire so as to figure out incomprehensive or confusing words, examining the suitability of the question content, determining flaws in the initial draft and finally assessing the rating scale.

Quantitative research was implemented through the following stages: designing the research sample, collecting data from survey panels, data analysis by SPSS 20 including Exploratory Factor Analysis (EFA), Cronbach's Alpha Test and regression analysis. First, we used EFA tool on SPSS 20 and eliminated variables with small parameter by checking the factor loading and the extracted variances; assessing the suitability of the model via KMO coefficient (Kaiser-Meyer-Olkin). Next, the scale was assessed by Cronbach's Alpha reliability coefficient. Then, we ran the regression model to test the suitability of the model and examined the effects of factors on the application of legitimate documents of Accounting in Vietnamese SMEs.

\section{Result and Discussion}

In the survey, we offered 30 variables divided into 8 factors. To test the division of factors, we used the result acquired from the summary of 548 eligible answers and input variables into EFA to take out factors; in the meantime, we dismissed variables with low coefficient which did not belong to any apparent factor. (variables were allocated to factors and we did not gather variables having bigger coefficients into a factor). As a result of respectively dismissing the following variables: NKT1; NQL1; LICP2; NQL2; NSD3; NQL3; NQL4, seven new factors were formed as follows. 
Table 2. Result of the first exploratory factor analysis (rotated component matrix ${ }^{\mathrm{a}}$

\begin{tabular}{|c|c|c|c|c|c|c|c|}
\hline & \multicolumn{7}{|c|}{ Components } \\
\hline & 1 & 2 & 3 & 4 & 5 & 6 & 7 \\
\hline CSHT4 & .762 & & & & & & \\
\hline CSHT2 & .759 & & & & & & \\
\hline CSHT1 & .714 & & & & & & \\
\hline CSHT3 & .707 & & & & & & \\
\hline NKT5 & .619 & & & & & & \\
\hline VBPL3 & & .817 & & & & & \\
\hline VBPL4 & & .797 & & & & & \\
\hline VBPL2 & & .734 & & & & & \\
\hline VBPL5 & & .592 & & & & & \\
\hline NKT4 & & & .840 & & & & \\
\hline NKT3 & & & .814 & & & & \\
\hline NKT2 & & & .722 & & & & \\
\hline TBB2 & & & & .777 & & & \\
\hline TBB3 & & & & .762 & & & \\
\hline TBB1 & & & & .692 & & & \\
\hline LICP3 & & & & & .716 & & \\
\hline LICP1 & & & & & .664 & & \\
\hline QMDN2 & & & & & .607 & & \\
\hline QMDN1 & & & & & .576 & & \\
\hline NSD2 & & & & & & .686 & \\
\hline NSD1 & & & & & & -.605 & \\
\hline QMDN3 & & & & & & & .725 \\
\hline VBPL1 & & & & & & & .699 \\
\hline
\end{tabular}

Note. Extraction Method: Principal Component Analysis; Rotation Method: Varimax with Kaiser Normalization; a. Rotation converged in 6 iterations.

The rating scales of these newly-formed factors need to be reassessed in terms of their reliability. Hence, in the next step we examined the Cronbach's Alpha coefficients to test the reliability of the rating scale through the observed variables, based on which we could exclude meaningless variables from this model. Besides, we checked the reliability of the rating scale measuring the application of legitimate documents of Accounting in Vietnamese SMEs.

Table 3. Testing the rating scale by Cronbach's Alpha reliability coefficient (reliability statistics item-total statistics)

\begin{tabular}{|c|c|c|c|c|c|}
\hline \multicolumn{6}{|c|}{ Rating scale of Factor No. 1, Cronbach's Alpha $=0.787$} \\
\hline \multirow{2}{*}{ Items } & \multirow{2}{*}{ Scale Mean if Item Deleted } & \multirow{2}{*}{ Scale Variance if Item Deleted } & \multicolumn{2}{|c|}{ Corrected Item-TotalCronbach's } & \multirow[t]{2}{*}{ Alpha if Item } \\
\hline & & & Correlation & Deleted & \\
\hline CSHT1 381 & 15.58 & 6.330 & .565 & .749 & \\
\hline CSHT2 382 & 15.53 & 6.471 & .633 & .724 & \\
\hline CSHT3 383 & 15.66 & 7.015 & .566 & .748 & \\
\hline CSHT4 384 & 15.59 & 6.975 & .570 & .746 & \\
\hline NKT5 355 & 15.55 & 6.914 & .500 & .768 & \\
\hline \multicolumn{6}{|c|}{ Rating scale of Factor No. 2, Cronbach's Alpha $=0.771$} \\
\hline VBPL2 312 & 10.36 & 4.323 & .530 & .737 & \\
\hline VBPL3 313 & 10.36 & 3.958 & .662 & .667 & \\
\hline VBPL4 314 & 10.36 & 3.961 & .651 & 673 & \\
\hline VBPL5 315 & 10.31 & 4.471 & .456 & .776 & \\
\hline \multicolumn{6}{|c|}{ Rating scale of Factor No. 3, Cronbach's Alpha $=0.774$} \\
\hline NKT2 352 & 6.68 & 3.181 & .564 & .744 & \\
\hline NKT3 353 & 6.72 & 2.938 & .633 & 670 & \\
\hline NKT4 354 & 6.71 & 2.879 & .633 & .669 & \\
\hline
\end{tabular}




\begin{tabular}{|c|c|c|c|c|}
\hline \multicolumn{5}{|c|}{ Rating scale of Factor No. 4, Cronbach's Alpha $=0.720$} \\
\hline TBB1 321 & 7.22 & 2.564 & .509 & .668 \\
\hline TBB2 322 & 7.35 & 2.345 & .603 & .556 \\
\hline TBB3 323 & 7.37 & 2.254 & .515 & .668 \\
\hline \multicolumn{5}{|c|}{ Rating scale of Factor No. 5, Cronbach's Alpha $=0.487$} \\
\hline LICP1 371 & 9.91 & 10.545 & .370 & .393 \\
\hline LICP3 373 & 9.99 & 10.381 & .377 & .384 \\
\hline QMDN1 331 & 9.87 & 9.997 & .367 & .375 \\
\hline QMDN2 332 & 9.88 & 4.837 & .281 & .617 \\
\hline \multicolumn{5}{|c|}{ Rating scale of Factor No. 6, Cronbach's Alpha $=-0.118$} \\
\hline NSD1 361 & 3.82 & .503 & -.056 &.$^{\mathrm{a}}$ \\
\hline NSD2 362 & 3.25 & .669 & -.056 &.$^{\mathrm{a}}$ \\
\hline \multicolumn{5}{|c|}{ Rating scale of Factor No. 7, Cronbach's Alpha $=0.151$} \\
\hline VBPL1 311 & 3.06 & .616 & .082 &.$^{\mathrm{a}}$ \\
\hline QMDN3 333 & 3.69 & .767 & .082 &..$^{\mathrm{a}}$ \\
\hline \multicolumn{5}{|c|}{ Rating scale measuring the application of legitimate documents of Accounting in Vietnamese SMEs, Cronbach's Alpha $=0.713$} \\
\hline VD1 411 & 10.88 & 3.890 & .621 & .576 \\
\hline VD2 412 & 11.07 & 4.166 & .515 & .641 \\
\hline VD3 413 & 11.08 & 4.444 & .350 & .745 \\
\hline VD4 414 & 10.85 & 4.158 & .536 & .629 \\
\hline
\end{tabular}

As can be seen in the test result of the rating scale measuring the application of Accounting legitimate documents Accounting in Vietnamese SMEs, the Cronbach's Alpha $=0.713(>0.6)$, the gross correlation coefficients are approximately or greater than 0.5 (much more than the acceptable level of 0.3 ); hence, the reliability of this rating scale is acceptable.

As regards the factors affecting the implementation of accounting legislation in Vietnamese SMEs, it can be well-noted that the Cronbach's Alpha coefficients of the factor no. 6 and 7 are relatively low $(0.118$ and 0.151 , respectively), which are much lower than the necessary level of 0.6. In other words, these factors are unreliable and should be eliminated. Real conditions in Vietnam indicate that with an underdeveloped capital market, users have less diverse needs for information and exert less significant pressure on information supply; thus, it can be assumed that they have no profound impact on the deployment of accounting legislation in Vietnamese SMEs. In addition, various levels of accounting legitimate documents as well as the financial resource for implementation have of no significant importance in applying the legitimate documents. In short, the elimination of these two factors is reasonable in terms of both theory and reality in Vietnam.

Regarding factor no. 5, among 4 observed variables in the rating scale if this factor, the variable called "QMDN2 332 " has the gross correlation coefficient lower than 0.3. Considering the exclusion of this variable of the rating scale, the Cronbach's Alpha will be on a considerable increase. In other words, this variable does not significantly contribute to the general meaning of the factor. In this case, we decided to eliminate this variable, accordingly, the second result of Cronbach's Alpha of factor no. 5 becomes 0.617 , which is within the acceptable reliability range.

Continuing with the analysis of the remaining 18 variables, $\mathrm{KMO}=0.816$ with the significance level Sig $=0.000$ and extracting 5 factors with the gross variance extracted $=61.28 \%$. To improve the exploratory capacity of these factors, the study chose Varimax rotation which serves to minimize the number of variables with high coefficient in the same factor. The result is demonstrated in the table as follows: 
Table 4. Result of the third exploratory factor analysis with varimax rotation (KMO and Bartlett's test)

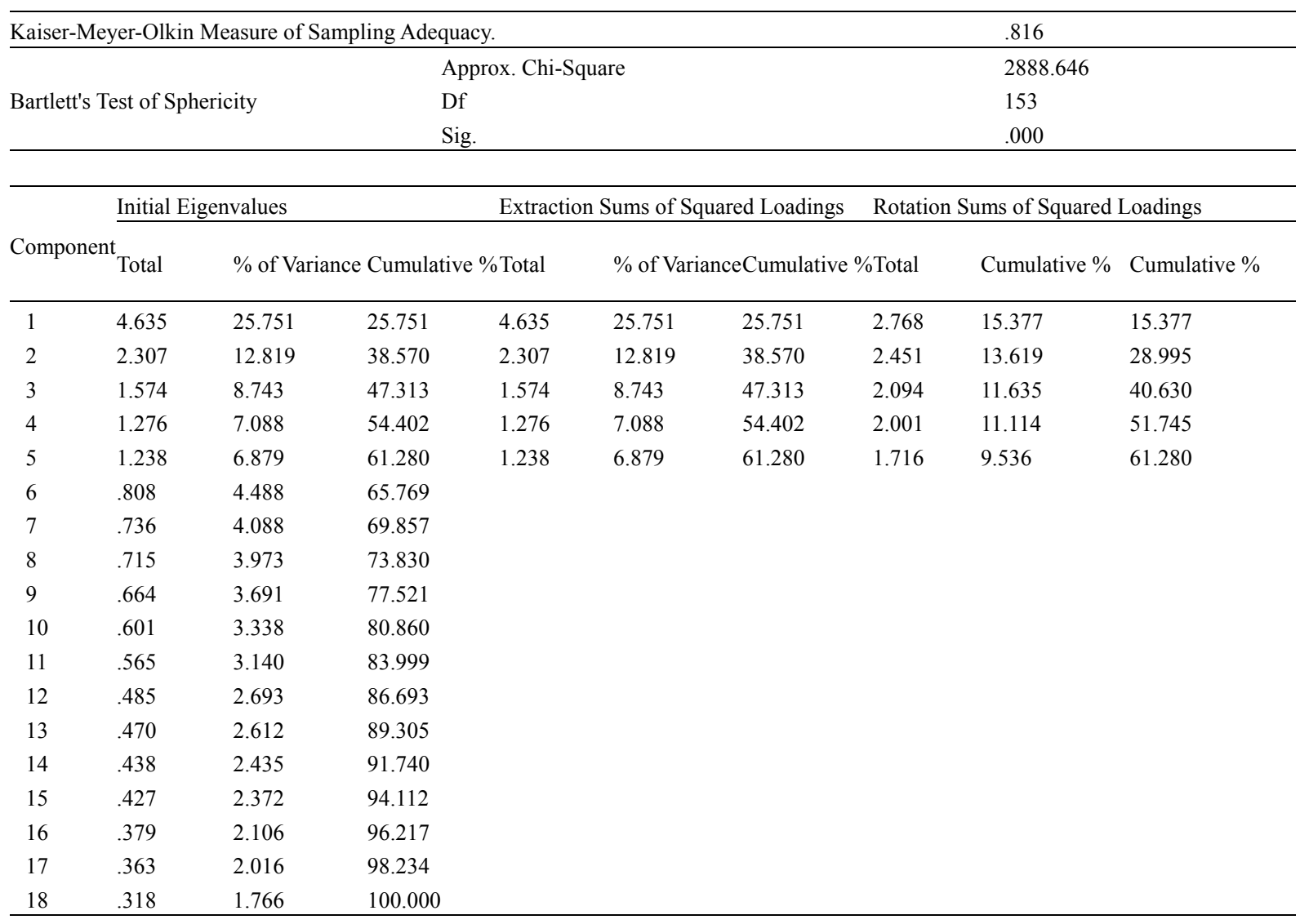

Extraction Method: Principal Component Analysis

Rotated Component Matrix ${ }^{\mathrm{a}}$

\begin{tabular}{|c|c|c|c|c|c|}
\hline \multicolumn{6}{|c|}{ Factor } \\
\hline & 1 & 2 & 3 & 4 & 5 \\
\hline CSHT2 382 & .766 & & & & \\
\hline CSHT4 384 & .748 & & & & \\
\hline CSHT3 383 & .722 & & & & \\
\hline CSHT1 381 & .719 & & & & \\
\hline NKT5 355 & .618 & & & .233 & \\
\hline VBPL3 313 & & .823 & & & \\
\hline VBPL4 314 & & .806 & & & \\
\hline VBPL2 312 & & .739 & & & \\
\hline VBPL5 315 & & .598 & & & \\
\hline NKT4 354 & & & .851 & & \\
\hline NKT3 353 & & & .821 & & \\
\hline NKT2 352 & & .222 & .728 & & \\
\hline TBB2 322 & .221 & & & .789 & \\
\hline TBB3 323 & & & & .759 & \\
\hline TBB1 321 & .212 & .200 & & .708 & \\
\hline LICP3 373 & & & & & .819 \\
\hline LICP1 371 & & & & & .766 \\
\hline QMDN1 331 & & & & .322 & .561 \\
\hline
\end{tabular}

Note. Extraction Method: Principal Component Analysis;

Rotation Method: Varimax with Kaiser Normalization;

a. Rotation converged in 6 iterations.

As can be seen, 5 factors with the gross variance extracted equal to $61,28 \%$, which means these 5 factors can 
explain for $61 \%$ of the application of accounting legislation in Vietnamese SMEs, the remaining $39 \%$ depends on other factors that are oversaw in this study.

The calibrated model comprises of 5 factors that have impact on the utilization of accounting legislation in Vietnamese SMEs, namely: factor no.1, which is referred to in our study as "Accounting infrastructure", with its rating scale relating to accounting infrastructure and experience of accountants; factor no. 2 called "The legal framework itself"; factor no. 3 called "Accountants"; factor no.4 called "mandatory compliance"; and the final factor called "Cost - benefit relationship".

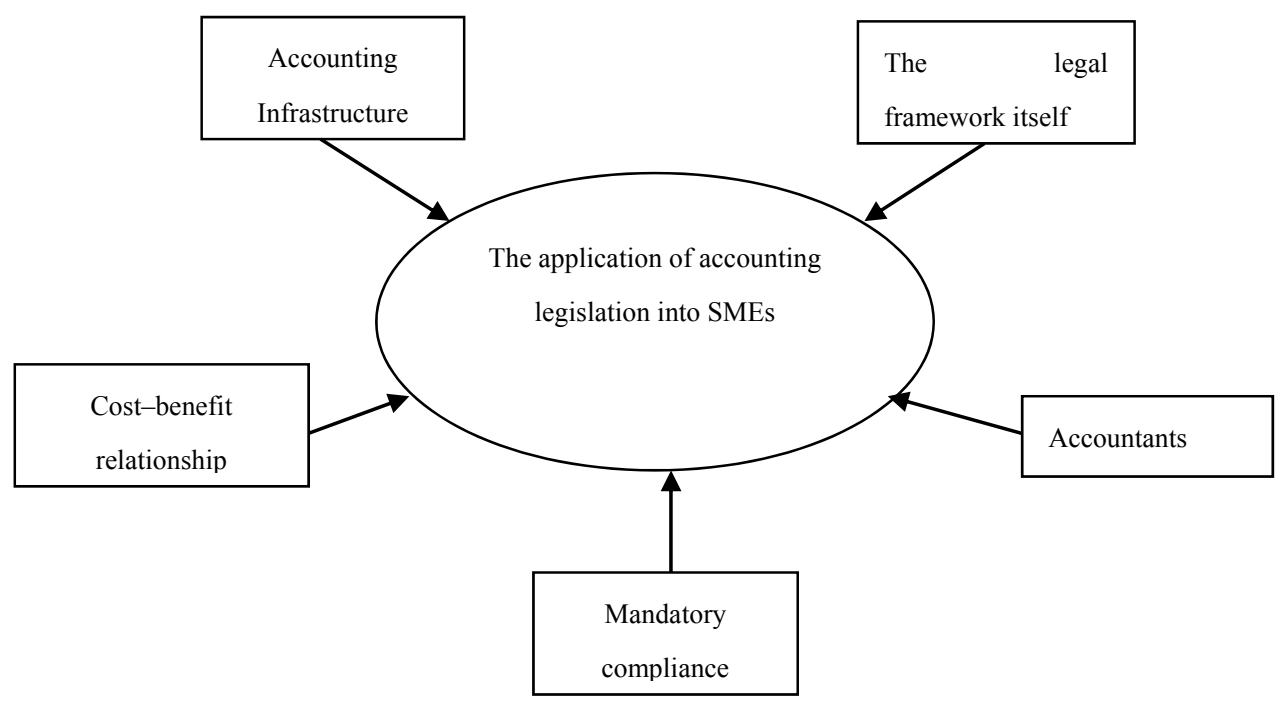

Figure 2. Calibrated model

After successfully developing the model of factors that affect the implementation of accounting legitimate documents into Vietnamese SMEs, we processed to assess this model by Multiple Regression (MLR) model to test its appropriateness and to examine the extent to which these factors influence the process of application. The result of MLR analysis generated by SPSS with "Enter" method is as follows.

Table 5. Result of assessing the calibrated model (model summary ${ }^{\mathrm{b}}$ )

\begin{tabular}{|c|c|c|c|c|c|c|}
\hline Model & $\mathrm{R}$ & R Square & & Adjusted R Square & & Std. Error of the Estimate \\
\hline 1 & $.630^{\mathrm{a}}$ & .397 & & .391 & & .78027699 \\
\hline \multicolumn{7}{|c|}{ ANOVA $^{b}$} \\
\hline Model & & Sum of Squares & $\mathrm{df}$ & Mean Square & $\mathrm{F}$ & Sig. \\
\hline \multirow[t]{3}{*}{1} & Regression & 217.013 & 5 & 43.403 & 71.288 & $.000^{\mathrm{a}}$ \\
\hline & Residual & 329.987 & 542 & .609 & & \\
\hline & Total & 547.000 & 547 & & & \\
\hline
\end{tabular}


Table 6. Result of MLR with individual regression coefficients in the model

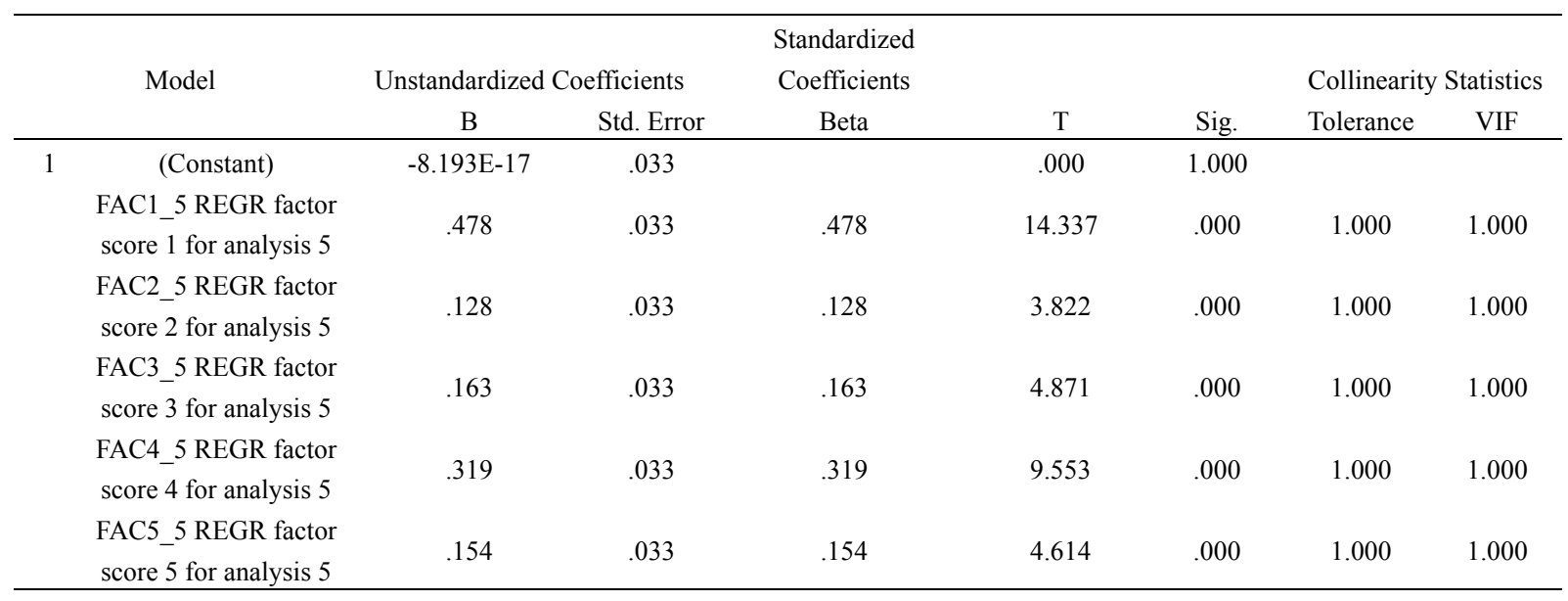

Note. a. Dependent Variable: FAC1_2 REGR factor score 1 for analysis 2.

MLR result shows that adjusted $\mathrm{R}^{2}=0.391, \mathrm{~F}$-test (ANOVA table) expresses the significance level sig. $=0.000$; thus, the regression model is suitable and these factors can explain $39.1 \%$ of the variations of the dependent variable. Considering the regression weights, we can identify the positive correlation between these factors and $\mathrm{Y}$, these variables are statistically significant due to do sig. $=.000$ ), there is no sign of multicollinearity, or to be specific, these variables are not inter-correlated. Also, based on high Beta coefficient, the factor no. 1 is of the most importance and has the most significant impact on the application of accounting legal documents in Vietnamese SMEs. Coming second is the factor no.4 relating to the mandatory compliance. The influential degree of the remaining factors is factor no.3 (Accountants), factor no.5 (Cost-benefit relationship) and factor no. 2 (Accounting legislation) in descending order.

\section{Conclusion}

It is of great importance and practice to conduct a research model on the factors affecting the application of accounting legitimate documents in Vietnamese SMEs as well as their influential level. Based on these findings, we can propose a range of solutions to facilitate a fast and efficient implementation in the reality. According to the result of this study, major factors exerting considerable effect on the process of application (in the descending order of impact): Accounting infrastructure, Mandatory compliance of the regulations, Accountants, Cost benefit relationship and Accounting legitimate documents themselves. This finding is crucial to advise plausible solutions to effectively implement these accounting legal documents into practice.

\section{References}

Cătălin, N. A., Nadia, A., \& Szilveszter, F. (2010). The context of the possible IFRS for SMEs implementation in Romania, An exprolatory Study. Accounting And Management Information Systems, 9(1), 45-71.

Dang, D. S. (2011). Compliance with accounting standards by SMEs in transitional economies: evidence from Vietnam. Journal of Applied Accounting Research, 12(2), 96-107. http://dx.doi.org/10.1108/09675421111160673

Daniel, Z., \& Karim, M. (2006). An analysis of the factors affecting the adoption of international accounting standards by developing countries. The International Journal of Accounting, 41, 373-386. http://dx.doi.org/10.1016/j.intacc.2006.09.009

Deaconu, A., Buiga, A., \& Strouhal, J. (2012). SMEs financial reporting: Attitudes towards IFRS for SMEs. Studia UBB, Oeconomica, 57(1), 101-122.

Ha, V. W., \& Rossouw, J. (2009). IFRS for SMEs in South Africa: a giant leap for accounting, but too big for smaller entities in general. Meditari Accountancy Research, 17(1), 99-116.

Hoang, T. P. T. (2012). Customer Relationship Development at Stock Commercial Banks in Ho Chi Minh City. Journal of Economic Development, 265. http://dx.doi.org/10.1108/10222529200900007

Nguyen, D. T. (2011). Research Methodology in Business-Design and Execution. Social and Labor Publishing House. 
Nguyen, D. T., \& Nguyen, T. M. T. (2009). Scientific Research in Business Administration. Statistics Press.

Pitachaya, K., \& Phapruke, U. (2012). Activity-Based Cost management strategy and continuous performance improvement: evidence of Thai electronic firms. International Journal of Strategic Management, 12(3).

Szilveszter et al. (2010). Explaining accounting policy choices of SME's: An empirical research on the evaluation methods. European Research Studies, 13(1), 33-48.

Tran, D. K. N. (2010). Discussion on model of factors affecting accounting deployment in SMEs. Journal of Science and Technology, 5(40).

Tran, D. K. N. (2011). Factors affecting accounting deployment in SMEs in Đà Nẵng. Journal of Economic Development, 252, 9-15.

Tran, D. K. N. (2013). Discussion on unfinancial factors affecting accounting deployment in SMEs in Vietnam. Journal of Economics and Development, 194, 54-60.

\section{Copyrights}

Copyright for this article is retained by the author(s), with first publication rights granted to the journal.

This is an open-access article distributed under the terms and conditions of the Creative Commons Attribution license (http://creativecommons.org/licenses/by/3.0/). 